\title{
Determination of essential and toxic elements, ascorbic acid content and color of different leaves in two cabbage varieties
}

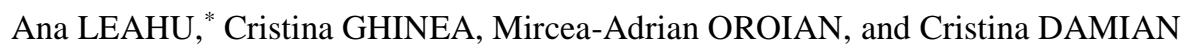 \\ Stefan cel Mare University of Suceava, Romania, Faculty of Food Engineering, $13^{\text {th }}$ University Street, Suceava, \\ Romania
}

\begin{abstract}
The main goal of this paper was to evaluate total macro- and microelement contents of different cabbage leaves of two varieties of cabbage (Brassica oleracea var. capitata f. alba and Brassica oleracea var. capitata f. rubra) and to determine the ascorbic acid content and color parameters $\left(L^{*}, a^{*}, b^{*}\right.$ and $\left.-\Delta E\right)$. Also, the anthocyanins content of Brassica oleracea var. capitata f. rubra was investigated. The highest mean contribution of elemental interactions regarding total macroelements in white cabbage leaves from inside (14-16 leaf), was observed for calcium and selenium, whereas the lowest was found for heavy metals, nickel, cadmium, and cobalt. The total contents of calcium and selenium in red cabbage leaves from inside (14-16 leaf) were highest. Results showed that the red-purple hue is more pronounced outside of the red cabbage than inside and it was also found that there are losses of yellowish hues for white cabbage from the outer leaves to the inner ones. Regarding the content of anthocyanins, it was obtained a value of $65.124 \mathrm{mg} / 100 \mathrm{~g}$ fresh weigh for outer leaves of red cabbage. Our results indicated that ascorbic acid content of red cabbage is approximately 3 times higher than in the white cabbage.
\end{abstract}

Keywords: cabbage leaves, heavy metals, ascorbic acid, color parameters, total anthocyanins content.

\section{Introduction}

In recent decades, fresh vegetables have been investigated, due to their potential as health promoting phytochemicals, such as polyphenols, ascorbic acid which prevent cell damage caused by free radicals and dietary fiber and therefore responsible for this protective effect. The antioxidant properties of cabbage polyphenols are responsible for their antiviral and antiinflammatory properties and reduce the risk of heart disease, neurodegenerative diseases, and diabetes [1] Important sources of dietary polyphenols are beverages, fruits and vegetables. It is considered that the average daily intake of polyphenols is $1 \mathrm{~g}$ per person [2, 3]. Brassica vegetables consumption has significantly benefits on human health by reducing the risk of chronic diseases, having potential anticarcinogenic and being extensively researched in recent years [4 - 6].

White cabbage (Brassica oleracea L. var. Capitataf. $A l b a)$ has its origins in the Mediterranean region and since ancient times has been considered a healthpromoting vegetables. Today, this dietary vegetable is consumed in large quantities both in Europe and around the world being preferred by consumers due to its availability and low price. Besides that, brassica vegetables contain health-promoting compounds: high levels of glucosinolates (GLS), polyphenols, carotenoids, tocopherols, and vitamins [5]. Bioactive compounds present in white and red cabbage, such as water-soluble vitamin $\mathrm{C}$ and phenolic compounds (lignans, flavonoids and phenolic acids), as well as lipid-soluble vitamin $\mathrm{E}$ and carotenoids, are important contributors to the defense against oxidative stress [7]. According to the Kusznierewicz et al. [4] who studied the antioxidative compounds of white cabbage samples derived from four European countries, the highest total polyphenols content was identified for cabbage from Belgium (4.917 \pm 0.52 $\mathrm{mg}$ gallic acid equivalents (GAE)/g dry weight) comparative with the samples from other regions. Tanongkankit et al. [8], studied the effect of vacuum drying at 60,70 and $80^{\circ} \mathrm{C}$ on the phenolic compounds and vitamin $\mathrm{C}$, in white cabbage outer leaves. They stated that under all conditions tested there were no differences in antioxidant retention.

Consumption of dietary fiber has an important role in many physiological processes and in the prevention of diseases such as constipation, hemorrhoids, irritable colon, colon cancer, obesity and diabetes. It has been scientifically proven that cabbage is a good source of dietary fiber. Considering the benefit of dietary fiber, the World Health Organization (WHO) recommends for adults an intake of $25 \mathrm{~g}$ total fiber/day [9]. The cabbage outer leaves that usually are removed during industrial processing are in fact an important source of dietary fiber, having also a high content of vitamin $\mathrm{C}$ and polyphenols [8].

The essential mineral elements content of cabbage is represented by calcium $(\mathrm{Ca})$, potassium $(\mathrm{K})$, magnesium $(\mathrm{Mg})$ and phosphorous $(\mathrm{P})$, and essential or potentially essential trace elements: cobalt $(\mathrm{Co})$, copper $(\mathrm{Cu})$, iron $(\mathrm{Fe})$, manganese $(\mathrm{Mn})$, nickel $(\mathrm{Ni})$, selenium $(\mathrm{Se})$ and zinc $(\mathrm{Zn})$. Copper, chromium, iron and zinc play an important role in human, animal and plant cell metabolism. Copper can be found in many enzymes, some of which are essential for Fe metabolism and various studies have reported a direct correlation between the dietary $\mathrm{Zn} / \mathrm{Cu}$ ratio and the incidence of cardiovascular disease [10]. Iron is constituent of catalase

*Corresponding author. E-mail address: analeahu@gmail.com (Ana Leahu) 
(a heme protein) and is essential for the transport of oxygen from the lungs to the tissues as well as the transport of carbon dioxide. Zinc enzymes participate in a wide variety of metabolic processes including carbohydrate, lipid and protein synthesis or degradation [10]. It has been demonstrated that a high intake of vegetables through high potassium content reduces the risk of coronary heart disease (CHD), high blood pressure and stroke [11]. Bvenura and Afolayan investigated the accumulation of $\mathrm{Cu}, \mathrm{Mn}, \mathrm{Zn}, \mathrm{Pb}$ and $\mathrm{Cd}$ in different vegetables (including cabbage). Their results showed that the type of cabbage analyzed contained: $28.85 \mathrm{mg} / \mathrm{kg} \mathrm{Mn}, 27.38 \mathrm{mg} / \mathrm{kg} \mathrm{Zn}, 0.62 \mathrm{mg} / \mathrm{kg} \mathrm{Cu}, 0.24$ $\mathrm{mg} / \mathrm{kg} \mathrm{Cd}$ and $\mathrm{Pb}$ concentration below the detection limit [12]. Stančić et al. investigated the heavy metals content in the vegetables like lettuce, cabbage, potato and others from one Croatian market. The results of their study indicated that $\mathrm{Cd}$ was presented in cabbage in concentration between $0.10-0.24 \mathrm{mg} / \mathrm{kg}$, Cu between 2.1 $3.4 \mathrm{mg} / \mathrm{kg}$ and $\mathrm{Mn}$ from 8.7 to $21.9 \mathrm{mg} / \mathrm{kg}$ [13]. Radulescu et al. determined the bioaccumulation of heavy metals in Brassica oleracea L. var. capitata, considering different parts of the plant: outer and interior leaves, core, interior and exterior stem, root. According to their results $\mathrm{Cu}$ concentration exceeds the value (5 $\mathrm{mg} / \mathrm{kg}$ ) admitted by Romanian legislation for all samples, while $\mathrm{Cd}$ accumulates in high concentration in all samples excepting the exterior stem and root of cabbage [14].

The aim of this study was to characterize mineral content, to determine ascorbic acid content, to establish color parameters of different white and red cabbage leaves, and to investigate the anthocyanins content of red cabbage leaves.

\section{Experimental}

\subsection{Chemicals}

1,1-diphenyl-2-picrylhydrazyl (DPPH), methanol, monopotassium phosphate, orthophosphoric acid, nitric acid and standard L- ascorbic acid were purchased from Sigma (Germany). Deionized water was used throughout.

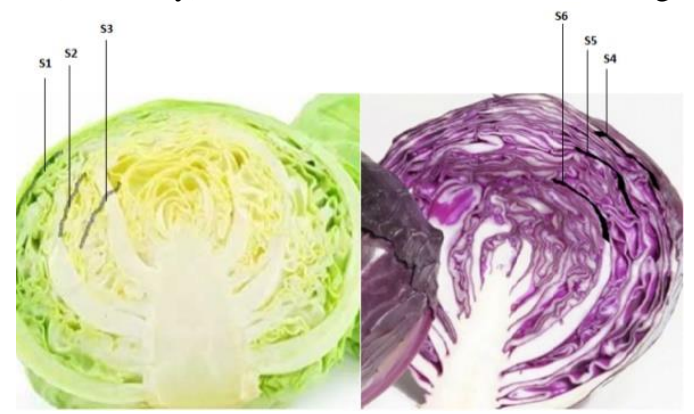

Figure 1. Samples for analysis of white and red cabbage leaves (outer (S1, S4), mid (S2, S5) and inner layer (S3, S6).

\subsection{Samples}

The samples (Brassica oleracea var. capitataf. alba and Brassica oleracea var. capitata f. rubra) were harvested in autumn 2017 at the site Milisauti. Figure 1 shows the layers of cabbage leaves. For the determinations, the leaves 1-3 were used from the outside of the cabbage head (S1 and S4), after removed a few leaves. From the center of the cabbage, leaves were taken corresponding to the leaves 6-8 (S2 and S5), and from the inside of the vert, the leaves 14-16 (S3 and S6). The cabbage extracts were prepared in the laboratory immediately after collection and transport.

\subsection{Chemical analyses}

Color measurements. Minolta Chroma Meter (Model CR 310, Minolta Camera Co. Ltd., Japan) device was used to calculate directly three variables $L^{*}$ (lightness), $a^{*}$ (redness), and $b^{*}$ (yellowness) of the samples, using the average of 3 readings per sample [15].

HPLC analyses. High performance liquid chromatography was used in order to determine the ascorbic acid content of the samples. For this purpose, 4 $\mathrm{g}$ of cabbage samples was extracted with $12 \mathrm{ml}$ of acidified solutions (perchloric acid and $o$-phosphoric acid $1 \%$ ). The extraction was considered to be complete when solvents became colorless (the total solvent volume was $50 \mathrm{ml}$ ). Filter paper Whatman no. 1 was used for extracts filtration, after that the extracts were maintained at $-20^{\circ} \mathrm{C}$ [15].

Ascorbic acid was determined by using SHMADZU system coupled with UV-VIS detector (DAD). ZORBAX - C18 column $(5 \mu \mathrm{m}, 250 \times 4.6)$ was eluted in isocratic system with a mobile phase consisted of phosphate buffer $\mathrm{pH}=3.5$ (TFA): solution $0.02 \mathrm{ml}$ of monopotassium phosphate and orthophosphoric acid $10 \%$, adjusted to $\mathrm{pH}=3.5$ at a flow rate of $0.6 \mathrm{ml} / \mathrm{min}$. The chromatograms were registered at $245 \mathrm{~nm}$.

Sigma $99 \%$ standard $L$ ascorbic acid was used for the identification and a calibration curve was obtained based on dilutions of this standard solution in bidistilled water [15].

Total anthocyanins content in red cabbage was determined by UV-VIS spectrophotometer, according to Harzallah et al. [16]. Absorbance was measured at 530 and $657 \mathrm{~nm}$, and pigment content was expressed as cyanidin-3-glucoside (cyd-glu, molar extinction coefficient of $26,900 \mathrm{~L} \mathrm{~cm}^{-1} \mathrm{~mol}^{-1}$ and molecular weight of $449.2 \mathrm{~g} \mathrm{~mol}^{-1}$ ).

Four grams of sample were vortexed for $1 \mathrm{~min}$ in 40 $\mathrm{mL}$ of 85:15 (v/v) methanol/0.1 M HCl) and incubated for $24 \mathrm{~h}$ at room temperature in the dark. The mixture was then centrifuged at $10.000 \mathrm{rpm}$ for $10 \mathrm{~min}$, and the supernatant was recovered. The absorbance of the resulting solutions was measured at 530 and $657 \mathrm{~nm}$ using a spectrophotometer T70 UV-VIS PG Instruments Ltd. Samples were diluted so that absorbance readings at $530 \mathrm{~nm}$ were less than 1.2. They were allowed to equilibrate for $15 \mathrm{~min}$ before absorbance at 530 and 657 $\mathrm{nm}$ and the control was conducted in the same manner, except that the distilled water was used instead of sample. All determinations were carried out in triplicate.

The difference in absorbance $(A)$ between $530 \mathrm{~nm}$ $\left(A_{530} \mathrm{~nm}\right)$ and $657 \mathrm{~nm}\left(A_{657 \mathrm{~nm}}\right)$ wavelengths was calculated (Eq. 1):

$$
A=A_{530 \mathrm{~nm}}-0.25 \times A_{657 \mathrm{~nm}}
$$

The concentration of monomeric anthocyanin pigment was obtained (Eq. 2):

Anthocyanins content $(\mathrm{mg} / \mathrm{g})=\frac{A \times M W \times D F \times 1000}{\varepsilon \times 1}$ 
where $M W$ is the molecular weight (449.2 $\mathrm{g} / \mathrm{mol}), D F$ is the dilution factor, $\varepsilon$ is the molar absorptivity $(\varepsilon=26.900$ $\mathrm{L} / \mathrm{cm} / \mathrm{mg}$ ) for cyanidin-3-glucoside was used, and 1 is for a standard $1 \mathrm{~cm}$ path length. Total monomeric anthocyanins were reported as milligrams anthocyanins per $100 \mathrm{~g}$ fresh weight (mg cyanidin-3-glucoside/100 g fw) [16].

Total ash composition was obtained by calcination of $5 \mathrm{~g}$ of sample at $600{ }^{\circ} \mathrm{C}$ for $240 \mathrm{~min}$ in an electric furnace (SR ISO 763: 2008). The resulted ash was transferred into a $25 \mathrm{~mL}$ volumetric flask, where it was dissolved by adding a mixture of nitric acid $65 \%$ and deionized water.

Concentrations of mineral content in the filtrate of ash samples were estimated by using a mass spectrometer with inductively coupled plasma (ICP-MS) Agilent Technologies 7500 Series (Agilent, USA). The ICP-MS parameters were: nebulizer $0.9 \mathrm{~mL} / \mathrm{min}$, RF power 1500 $\mathrm{W}$, carrier gas $0.92 \mathrm{~L} / \mathrm{min}$, makeup gas $0.17 \mathrm{~L} / \mathrm{min}$, mass range 7-205 a.m.u. (atomic mass unit), integration time $0.1 \mathrm{~s}$, acquisition $22.76 \mathrm{~s}$. Detector parameters were: discriminator $8 \mathrm{mV}$, analogue $\mathrm{HV} 1770 \mathrm{~V}$ and pulse $\mathrm{HV}$ $1070 \mathrm{~V}$.

\subsection{Statistical analyses}

Three samples of each white or red cabbage were analyzed in order to obtain the contents of ascorbic acid, anthocyanins, minerals and color. All assays were carried out in triplicate. The obtained data were analyzed by using Minitab software version 17, one - way ANOVA was applied for statistical evaluation and Tukey method was used for comparisons.

\section{Results and discussion}

Color analysis. The chromatic characteristics of the white and red cabbage leaves (outer, central and inner layer) samples shown in Tables 1 and 2. A color parameter studied was brightness, $L^{*}$, the colorimetric parameter used to characterize the color variation of food during processing.

Table 1. Color parameters in white cabbage samples

\begin{tabular}{|l|c|c|c|c|}
\hline & \multicolumn{4}{|c|}{ Color parameters } \\
\hline & $\boldsymbol{L}^{\boldsymbol{*}}$ & $\boldsymbol{a}^{\mathbf{*}}$ & $\boldsymbol{b}^{\mathbf{*}}$ & $\boldsymbol{\Delta}^{\mathbf{4}}$ \\
\hline S1 & 80.8 & -5 & 32.81 & 32.48 \\
\hline S2 & 84.6 & -1.95 & 18.14 & 17.34 \\
\hline S3 & 86.13 & -2.08 & 17.84 & 16.22 \\
\hline
\end{tabular}

$L^{* 1}$ - lightness; $a^{* 2}$ - indicates red for positive value and green for negative value; $b^{* 3}$ - indicates yellow for positive value and blue for negative value; $\Delta E^{4}$ - total change in color.

Table 2. Color parameters and total monomeric anthocyanins in red cabbage samples

\begin{tabular}{|l|c|c|c|c|c|}
\hline & \multicolumn{4}{|c|}{ Color parameters } & $\boldsymbol{T M A}^{\mathbf{1}}$ \\
\hline & $\boldsymbol{L}^{\boldsymbol{* 3}}$ & $\boldsymbol{a}^{\boldsymbol{*}}$ & $\boldsymbol{b}^{\boldsymbol{* 5}}$ & $\boldsymbol{\Delta E}^{\mathbf{6}}$ & \\
\hline S4 & 23.96 & 3.59 & -1.04 & 71.5 & 65.124 \\
\hline S5 & 24.89 & 6.84 & -3.43 & 71.4 & 52.874 \\
\hline S6 & 25.87 & 8.84 & -3.91 & 71.9 & 21.541 \\
\hline
\end{tabular}

$T M A^{1}$ - total monomeric anthocyanins mg cy-3-gluE, $\mathrm{mg} / 100 \mathrm{~g}$ fw (fresh weight of cabbage); $L^{* 3}$ - lightness; $a^{* 4}$ - indicates red for positive value and green for negative value; $b^{* 5}$ - indicates yellow for positive value and blue for negative value; $\Delta E^{6}$ - total change in color.

As expected, the $L^{*}$ value is different for the three sample leaves of the white cabbage raw materials. Inside samples in cabbage induced slight color changes with $\Delta E$ values for S2 and S3 cabbage leaves of 17.34 and 16.22, respectively. The reduction in $b^{*}$ from 32.81 to 17.84 indicated losses of yellowish hues.

One of the parameters used to characterize the color variation is the total color difference $\Delta E^{*}$, since it is a combination of the parameters $L^{*}, a^{*}$ and $b$.

It was observed that the total change in color $\Delta E^{*}$ increased from the outer leaves to the inner layer red cabbage (Table 2).

The lightness $\left(L^{*}\right)$ for the samples showed an increasing tendency to 25.87 , which means that the redpurple hue is more pronounced outside the red cabbage than inside it. The outer leaves of red cabbage always showed lower total color difference $\Delta E^{*}$ and $L^{*}$, and higher anthocyanin levels, a synonym of redder and darker leaves.

Ascorbic acid $C$ levels in white cabbage leaves vary between 158.965 (S1) and $163.52 \mathrm{mg} / 100 \mathrm{~kg}$ fw of cabbage (S3), whereas for red cabbage the concentration is $490.214 \mathrm{mg} / \mathrm{kg}$ of S4 and for $\mathrm{S} 6,487.003 \mathrm{mg} / \mathrm{kg}$ of cabbage (Figure 2).

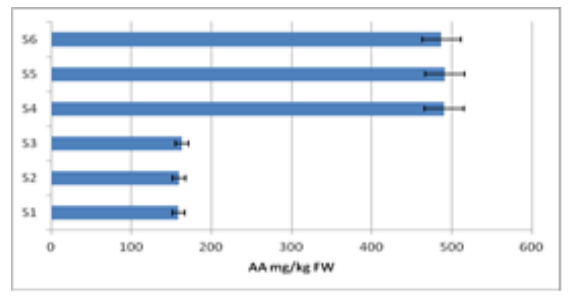

Figure 2. Ascorbic acid $(\mathrm{mg} / \mathrm{kg} \mathrm{fw})$ - of white and red cabbage leaves (outer (S1, S4), mid (S2, S5) and inner layer $(\mathrm{S} 3, \mathrm{~S} 6)$ used for analysis.

The vitamin $\mathrm{C}$ content of red cabbage is approximately 3 times higher than in the white cabbage (Figure 2). White cabbage cultivated in summer are rich source of ascorbic acid $(37.3 \mathrm{mg} / 100 \mathrm{~g} \mathrm{fw})$ compared to cabbage cultivated in winter $(27.9 \mathrm{mg} / 100 \mathrm{~g} \mathrm{fw})$ [5].

Anthocyanin levels in red cabbage were as follows: $65.124 \mathrm{mg} / 100 \mathrm{~g}$ fw for outer leaves (S4) and $21.541 \mathrm{mg} /$ $100 \mathrm{~g}$ for inner leaves. Podsedek et al. [7] reported the anthocyanin levels for red cabbage ( $40.53 \mathrm{mg} / 100 \mathrm{~g} \mathrm{FW}$ - $76.16 \mathrm{mg} / 100 \mathrm{~g} \mathrm{FW}$ ). The anthocyanin rich red cabbage showed high vitamin $\mathrm{C}$ contents and correspondingly high anti-oxidant activity.

Table 3. Limit of detection (LOD), limit of quantification (LOQ), precision, recovery for the 13 elements analyzed using ICP-MS.

\begin{tabular}{|c|c|c|c|c|}
\hline Analyte & $\begin{array}{c}\text { LOD } \\
(\boldsymbol{\mu g} / \mathbf{L})\end{array}$ & $\begin{array}{c}\text { LOQ } \\
(\boldsymbol{\mu g} / \mathbf{L})\end{array}$ & $\begin{array}{c}\text { Precision } \\
(\mathbf{C V} \%)\end{array}$ & $\begin{array}{c}\text { Recovery } \\
(\boldsymbol{\%})\end{array}$ \\
\hline $\mathrm{Na}$ & 115.125 & 348.829 & 3.89 & 98 \\
\hline $\mathrm{Mg}$ & 1.212 & 3.672 & 4.05 & 99 \\
\hline $\mathrm{Al}$ & 3.812 & 11.55 & 3.21 & 97 \\
\hline $\mathrm{Ca}$ & 3.156 & 9.563 & 4.87 & 96 \\
\hline $\mathrm{Cr}$ & 0.592 & 1.794 & 2.93 & 97 \\
\hline $\mathrm{Mn}$ & 0.456 & 1.382 & 4.21 & 99 \\
\hline $\mathrm{Fe}$ & 0.829 & 2.512 & 4.87 & 99 \\
\hline $\mathrm{Co}$ & 86.254 & 261.35 & 4.09 & 103 \\
\hline $\mathrm{Ni}$ & 0.261 & 0.791 & 3.26 & 95 \\
\hline $\mathrm{Cu}$ & 0.346 & 1.048 & 4.21 & 98 \\
\hline $\mathrm{Zn}$ & 22.659 & 68.657 & 2.98 & 98 \\
\hline $\mathrm{Se}$ & 1.61 & 4.878 & 1.92 & 104 \\
\hline $\mathrm{Cd}$ & 62.624 & 189.751 & 1.95 & 104 \\
\hline
\end{tabular}


Method of validation. Determination of all 13 elements was performed simultaneously with ICP-MS after acid mineralization. According to [17], two important performance characteristics were calculated: limits of detection (LOD) and limits of quantification (LOQ). The calculation of LOD and LOQ was performed considering three and ten times the standard deviation of the blank divided by the slope of the analytical curve, respectively [17]. LOD, LOQ, precision and recovery values for the analyzed elements are presented in Table 3.

The elemental concentrations. In recent years, a much discussed subject is the human health risk due to the bioaccumulation of heavy metals in the vegetables.

Table 4. Selected metal concentrations $(\mathrm{mg} / \mathrm{kg})$ in cabbage leaves

\begin{tabular}{|c|c|c|c|c|c|c|}
\hline \multicolumn{7}{|c|}{ Concentration [m/kg] } \\
\hline & \multicolumn{7}{|c|}{ White cabbage } & \multicolumn{3}{c|}{ Red cabbage } \\
\hline Element & $\mathrm{S} 1$ & $\mathrm{~S} 2$ & $\mathrm{~S} 3$ & $\mathrm{~S} 4$ & S5 & S6 \\
\hline $\mathrm{Na}$ & 38.5 & 49.0 & 55.0 & 50.0 & 46.5 & 55.0 \\
\hline $\mathrm{Mg}$ & 11.0 & 14.0 & 18.0 & 18.0 & 18.0 & 19.5 \\
\hline $\mathrm{Al}$ & 1.65 & 1.65 & 1.6 & 1.6 & 1.65 & 2.1 \\
\hline $\mathrm{Ca}$ & 650.0 & 700.0 & 750.0 & 1250.0 & 1200.0 & 1350.0 \\
\hline $\mathrm{Cr}$ & 55.0 & 100.0 & 85.0 & 95.0 & 95.0 & 105.0 \\
\hline $\mathrm{Mn}$ & 6.5 & 11.0 & 9.0 & 11.5 & 11.0 & 12.0 \\
\hline $\mathrm{Fe}$ & 4.9 & 8.57 & 6.3 & 6.75 & 7.47 & 6.85 \\
\hline $\mathrm{Co}$ & 0.16 & 0.225 & 0.185 & 0.215 & 0.230 & 0.215 \\
\hline $\mathrm{Ni}$ & 31.0 & 6.0 & 4.350 & 6.0 & 5.5 & 55.0 \\
\hline $\mathrm{Cu}$ & 8.0 & 3.3 & 3.15 & 4.0 & 3.45 & 3.6 \\
\hline $\mathrm{Zn}$ & 2.2 & 2.9 & 3.05 & 4.4 & 2.95 & 4.45 \\
\hline $\mathrm{Se}$ & 230.0 & 375.0 & 415.0 & 405.0 & 285.0 & 360.0 \\
\hline $\mathrm{Cd}$ & 0.750 & 1.100 & 1.250 & 1.450 & 1.350 & 1.550 \\
\hline
\end{tabular}

The elemental concentrations in the different leaves of white and red cabbage are summarized in Table 4 . The white and red cabbage had the highest mean concentrations of $\mathrm{Ca}, \mathrm{Se}$, and $\mathrm{Na}$. The $\mathrm{Ca}$ concentrations in the inner leaves were higher than in outer leaves. The highest concentrations of $\mathrm{Cr}$ were determined in the inner layer of red cabbage leaves and in the mid layer of white cabbage leaves. $\mathrm{Cr}$ concentrations in the other layers of red cabbage (outer, mid) are equal, while the lowest concentration of $\mathrm{Cr}$ was registered for outer layer of white cabbage. It can be seen that Co accumulates more in the mid layers of both cabbage types and also that red cabbage has a higher capacity to accumulate $\mathrm{Cd}$ compared to white cabbage (Table 4).

Statistical evaluation. One-way analysis of variance (ANOVA) was applied to determine if the group means are different. The $\alpha$-level used is the common one of 0.05. $p$-values obtained were compared with $\alpha$-value. In Table 5 are presented the values obtained for $\mathrm{Cr}, \mathrm{Co}, \mathrm{Ni}$, $\mathrm{Cu}, \mathrm{Zn}$ and $\mathrm{Cd}$. It can be observed that $p$-value for each element is 0.000 which means that some of the cabbage leaves have different means.

In Figure 3, in the interval plot S6 has the highest mean while S1 has the lowest mean. It can be observed that in Fig. 3b S5 has the highest mean, followed by S2.
The highest mean in the case of $\mathrm{Ni}$ investigation was registered for S6 followed by S1, while the other samples are almost in the same grouping categories (Fig. 3c).

In Fig. $3 \mathrm{~d}$ is shown that $\mathrm{S} 1$ has the highest mean, while $\mathrm{S} 3$ has the lowest mean. In the case of $\mathrm{Zn}$ and $\mathrm{Cd}$, S6 has the higher mean, while $\mathrm{S} 1$ the lowest one. The highest concentration of $\mathrm{Cr}, \mathrm{Ni}, \mathrm{Zn}$ and $\mathrm{Cd}$ is in $\mathrm{S} 6$ (red cabbage, inner leaves), while the lowest in S1 (white cabbage, outer leaves). Co is accumulating more in S5 (red cabbage, mid leaves) and less in S2 (white cabbage, mid leaves).

The means were compared by using Tukey Pairwise Comparisons in order to establish the group of means. In Table 6 were presented the values for means (when the amounts of $\mathrm{Cr}$ included in each sample were investigated) and the grouping categories for each sample. Samples S1, S2, S3, and S6 are significantly different while S4 and S5 are in the same group (the differences between the amount of $\mathrm{Cr}$ present in these samples are not statistically significant). The confidence interval includes zero only for S5-S4 (-1.374; 0.974) indicating also that the differences are not statistically significant. It was observed that for the remaining pairs of means all the confidence intervals do not include zero value

Table 5. Analysis of variance

\begin{tabular}{|l|c|c|c|c|c|}
\hline \multicolumn{1}{|c|}{ Source } & $\begin{array}{c}\boldsymbol{D F} \\
\text { (total degrees of freedom) }\end{array}$ & $\begin{array}{c}\text { Adj SS } \\
\text { (Adjusted sums) }\end{array}$ & $\begin{array}{c}\text { Adj MS } \\
\text { (Adjusted mean) }\end{array}$ & $\boldsymbol{F}$-value & $\boldsymbol{p}$-value \\
\hline Cr & & & & & \\
\hline Type of sample (TS) & 5 & 4830.32 & 966.065 & 5269.45 & 0.000 \\
\hline Error (E) & 12 & 2.20 & 0.183 & & \\
\hline Total (T) & 17 & 4832.52 & & & \\
\hline Co & 5 & 0.0100 & 0.0020 & 22.02 & 0.000 \\
\hline TS & 12 & 0.0011 & 0.00009 & & \\
\hline E & 17 & 0.0111 & & & \\
\hline T & \multicolumn{7}{|l}{} \\
\hline
\end{tabular}




\begin{tabular}{|c|c|c|c|c|c|}
\hline Source & $\begin{array}{c}D F \\
\text { (total degrees of freedom) }\end{array}$ & $\begin{array}{c}\text { Adj SS } \\
\text { (Adjusted sums) }\end{array}$ & $\begin{array}{c}\text { Adj MS } \\
\text { (Adjusted mean) }\end{array}$ & $F$-value & $p$-value \\
\hline \multicolumn{6}{|l|}{$\mathbf{N i}$} \\
\hline TS & 5 & 6478 & 1295 & 2342 & 0.000 \\
\hline E & 12 & 6.64 & 0.55 & & \\
\hline $\mathrm{T}$ & 17 & 6485 & & & \\
\hline \multicolumn{6}{|l|}{$\mathrm{Cu}$} \\
\hline $\mathrm{TS}$ & 5 & 44.34 & 8.86 & 37.98 & 0.000 \\
\hline $\mathrm{E}$ & 12 & 2.80 & 0.23 & & \\
\hline $\mathrm{T}$ & 17 & 47.14 & & & \\
\hline \multicolumn{6}{|l|}{$\mathbf{Z n}$} \\
\hline TS & 5 & 12.77 & 2.55 & 100.22 & 0.000 \\
\hline $\mathrm{E}$ & 12 & 0.30 & 0.025 & & \\
\hline $\mathrm{T}$ & 17 & 13.08 & & & \\
\hline \multicolumn{6}{|l|}{ Cd } \\
\hline TS & 5 & 1.228 & 0.2456 & 884.3 & 0.000 \\
\hline $\mathrm{E}$ & 12 & 0.003 & 0.0002 & & \\
\hline $\mathrm{T}$ & 17 & & & & \\
\hline
\end{tabular}

In Table 6 are presented the mean values for each sample and the grouping categories obtained for the other investigated elements $(\mathrm{Cr}, \mathrm{Co}, \mathrm{Ni}, \mathrm{Cu}, \mathrm{Zn}$, and $\mathrm{Cd})$ by using Tukey Method and 95\% confidence interval. It is considered that means which do not share a letter are significantly different. In order to determine how well the model fits the data $S$ and $R^{2}$ were calculated. It is considered that the model describes better the response when the value for $S$ is lower $(S=0.42$ for $\mathrm{Cr}, S=0.09$ for Co, $S=0.74$ for Ni, $S=0.48$ for $\mathrm{Cu}$ and $S=0.15$ for $\mathrm{Zn})$.

Table 6. Mean values and grouping categories for each sample obtained when $\mathrm{Cr}, \mathrm{Co}, \mathrm{Ni}, \mathrm{Cu}, \mathrm{Zn}$ and $\mathrm{Cd}$ values are investigated.

\begin{tabular}{|c|c|c|c|}
\hline Factor & N & Mean & Grouping \\
\hline \multicolumn{4}{|c|}{ Cr } \\
\hline S6 & 3 & 105.13 & A \\
\hline S2 & 3 & 100.33 & B \\
\hline S4 & 3 & 95.3 & C \\
\hline S5 & 3 & 95.1 & C \\
\hline S3 & 3 & 85.5 & D \\
\hline S1 & 3 & 55.33 & E \\
\hline \multicolumn{4}{|c|}{ Co } \\
\hline S5 & 3 & 0.226 & A \\
\hline S2 & 3 & 0.223 & A \\
\hline S6 & 3 & 0.215 & A \\
\hline S4 & 3 & 0.211 & A \\
\hline S3 & 3 & 0.185 & B \\
\hline
\end{tabular}

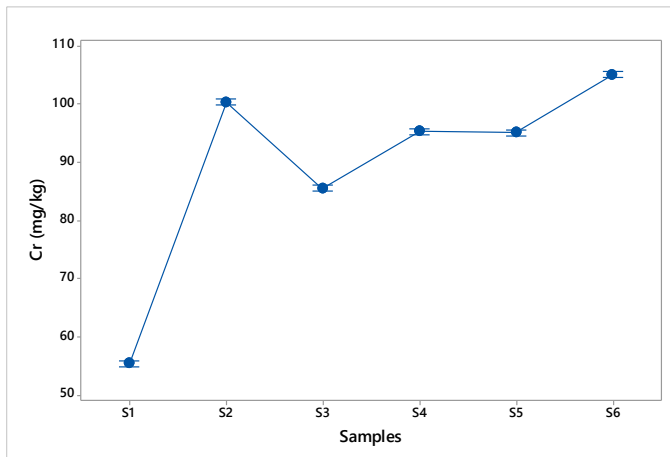

a)

\begin{tabular}{|c|c|c|c|}
\hline Factor & $\mathbf{N}$ & Mean & Grouping \\
\hline \multicolumn{4}{|c|}{$\mathbf{N i}$} \\
\hline S6 & 3 & 55 & $\mathrm{~A}$ \\
\hline $\mathrm{S} 1$ & 3 & 31 & $\mathrm{~B}$ \\
\hline $\mathrm{S} 2$ & 3 & 6.5 & $\mathrm{C}$ \\
\hline $\mathrm{S} 4$ & 3 & 6.0 & C D \\
\hline S5 & 3 & 5.4 & C D \\
\hline S3 & 3 & 4.2 & $\mathrm{D}$ \\
\hline \multicolumn{4}{|c|}{$\mathrm{Cu}$} \\
\hline $\mathrm{S} 1$ & 3 & 7.66 & $\mathrm{~A}$ \\
\hline $\mathrm{S} 4$ & 3 & 4.00 & $\mathrm{~B}$ \\
\hline S6 & 3 & 3.63 & $\mathrm{~B}$ \\
\hline S5 & 3 & 3.45 & B \\
\hline $\mathrm{S} 2$ & 3 & 3.33 & B \\
\hline $\mathrm{S} 3$ & 3 & 3.15 & $\mathrm{~B}$ \\
\hline \multicolumn{4}{|c|}{$\mathbf{Z n}$} \\
\hline S6 & 3 & 4.42 & A \\
\hline S4 & 3 & 4.40 & $\mathrm{~A}$ \\
\hline S3 & 3 & 3.06 & $\mathrm{~B}$ \\
\hline $\mathrm{S} 2$ & 3 & 2.90 & $\mathrm{~B}$ \\
\hline S5 & 3 & 2.70 & $\mathrm{~B}$ \\
\hline $\mathrm{S} 1$ & 3 & 2.20 & $\mathrm{C}$ \\
\hline \multicolumn{4}{|c|}{$\mathrm{Cd}$} \\
\hline S6 & 3 & 1.54 & $\mathrm{~A}$ \\
\hline $\mathrm{S} 4$ & 3 & 1.45 & B \\
\hline S5 & 3 & 1.34 & $\mathrm{C}$ \\
\hline S3 & 3 & 1.25 & $\mathrm{D}$ \\
\hline $\mathrm{S} 2$ & 3 & 1.08 & $\mathrm{E}$ \\
\hline $\mathrm{S} 1$ & 3 & 0.75 & $\mathrm{~F}$ \\
\hline
\end{tabular}

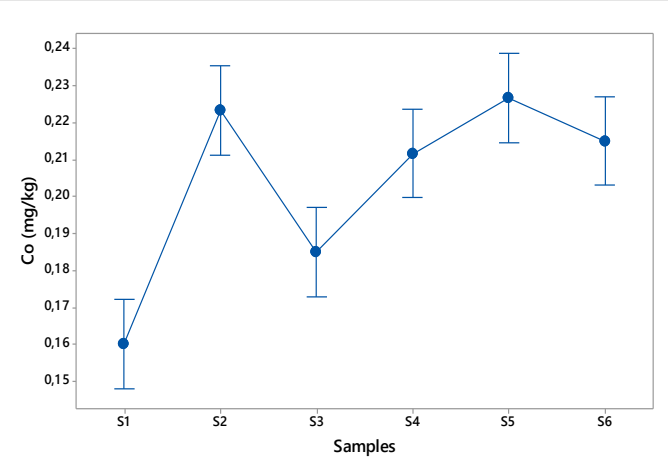

b) 


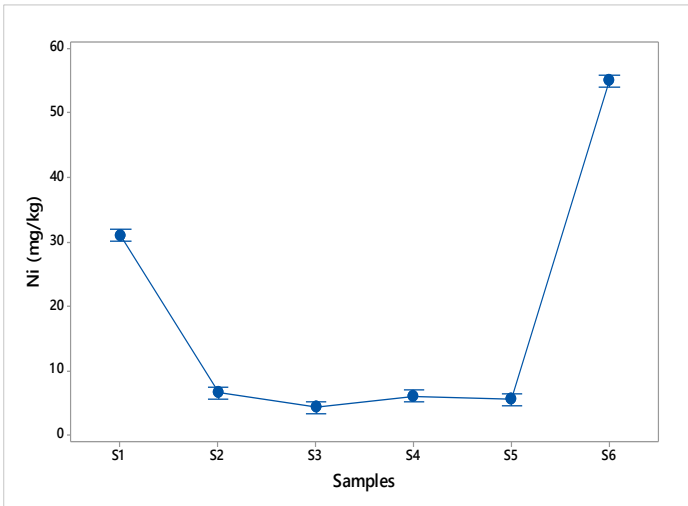

c)

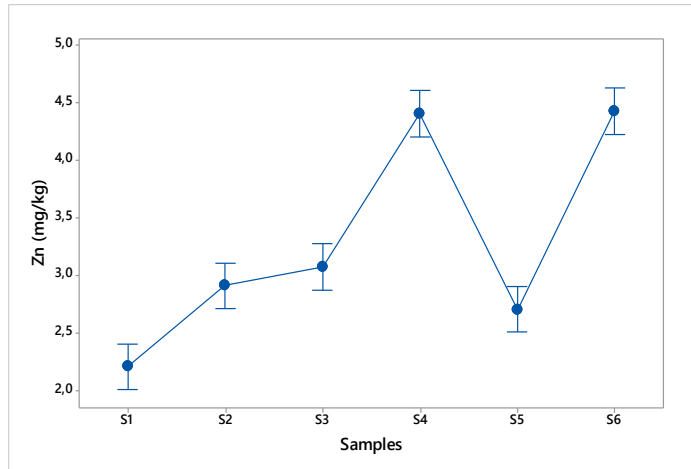

e)

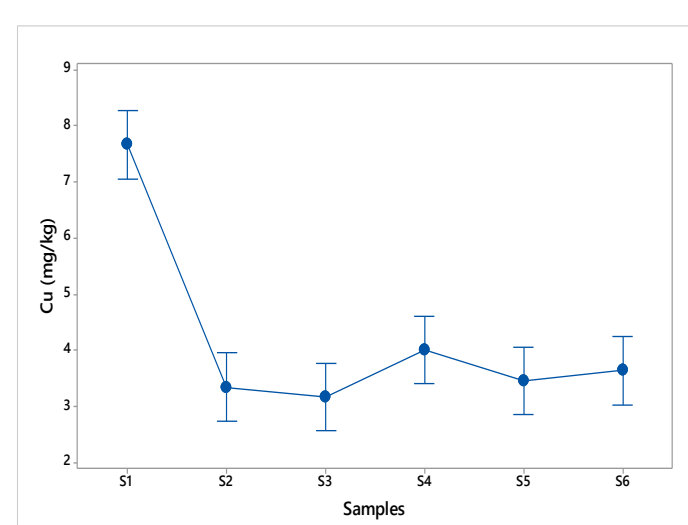

d)

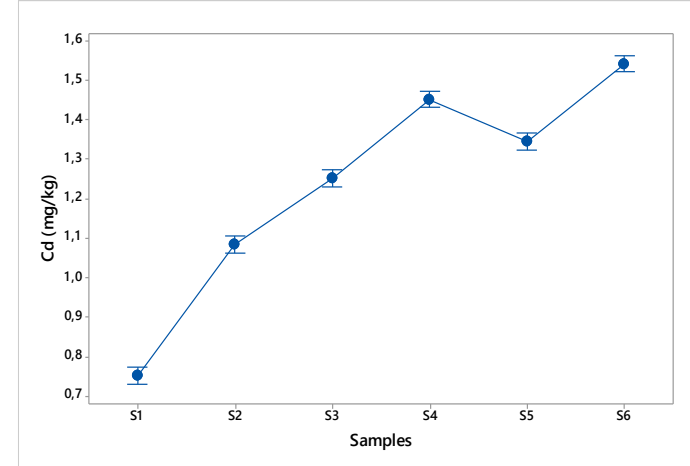

f)

Figure 3. Interval plot of $\mathrm{S} 1, \mathrm{~S} 2, \mathrm{~S} 3, \mathrm{~S} 4, \mathrm{~S} 5, \mathrm{~S} 6$ for six elements (Cr, $\mathrm{Co}, \mathrm{Ni}, \mathrm{Cu}, \mathrm{Zn}, \mathrm{Cd})$

Also, when high values were obtained for $R^{2}$ it can be assumed that the model fits the data. The values obtained for $R^{2}$ were: $99.9 \%$ for $\mathrm{Cr}, 90.17 \%$ for $\mathrm{Co}, 99.9 \%$ for $\mathrm{Ni}$, $94 \%$ for $\mathrm{Cu}, 97.6 \%$ for $\mathrm{Zn}$. These means that the values obtained for $R^{2}$ indicate that the predictors explain 99.9 $\%$ of the variance in $\mathrm{Cr}$ and $\mathrm{Ni}$, and only $90.17 \%$ of the variance in Co.

\section{Conclusions}

In this work, acid ascorbic, anthocyanins, macroelements, microelements, and heavy metal contents in different types of cabbage were determined. Color parameters were also investigated. Brassica vegetables have been used in human nutrition due to their rich nutritional value and low-calorie content, being grown in relatively cold areas. In red cabbage the evolution of color is a direct result of an increase in the levels of anthocyanins. The anthocyanins content of red cabbage will decrease for the inner layers as expected.

Results showed that the highest concentration of $\mathrm{Cr}$, $\mathrm{Ni}, \mathrm{Zn}$ and $\mathrm{Cd}$ is in red cabbage, inner leaves, while the lowest in white cabbage, outer leaves. In red cabbage, mid leaves a higher concentration of Co accumulates compared to the Co concentration that accumulate in white cabbage (mid leaves). After applying the Tukey Pairwise Comparisons results indicates that depending on the studied elements and especially on the concentrations in which they accumulate in different parts of the cabbage the samples may be significantly different or may be in the same group. It can be assumed based on the values obtained for $S$ that the model describes well the response. Higher values for $R^{2}$ were obtained which means that the model fits well with the data.

\section{Conflict of interest}

Authors declare no conflict of interest.

\section{References}

[1]. G.U. Seong, I.W. Hwang, S.K. Chung, Antioxidant capacities and polyphenolics of Chinese cabbage (Brassica rapa L. ssp. Pekinensis) leaves, Food Chemistry 199 (2016) 612-618.

[2]. A. Scalbert, C. Manach, C. Morand, C. Rémésy, L. Jiménez, Dietary polyphenols and the prevention of diseases, Critical reviews in food science and nutrition 45 (2005) 287-306.

[3]. F. Shahidi, P. Ambigaipalan, Phenolics and polyphenolics in foods, beverages and spices: Antioxidant activity and health effects-A review, Journal of functional foods 18 (2015) 820-897.

[4]. B. Kusznierewicz, A. Bartoszek, L. Wolska, J. Drzewiecki, S. Gorinstein, J. Namieśnik, Partial characterization of white cabbages (Brassica oleracea var. capitata f. alba) from different regions by glucosinolates, bioactive compounds, total antioxidant activities and proteins, LWT Food Sci. Tech. 41 (2008) 1-9.

[5]. C. Martinez-Villaluenga, E. Peñas, J. Frias, E. Ciska, J. Honke, M. K. Piskula, C. Vidal-Valverde, Influence of fermentation conditions on glucosinolates, ascorbigen, and ascorbic acid content in white cabbage (Brassica oleracea var. capitata cv. Taler) cultivated in different seasons, Journal of Food Science 74 (2009) C 62-7.

[6]. P. Soengas, T. Sotelo, P. Velasco, M. E. Cartea, Antioxidant properties of Brassica vegetables, 
Functional plant science and biotechnology 5 (2011) 43-55.

[7]. A. Podsedek, D. Sosnowska, M. Redzynia, B. Anders, Antioxidant capacity and content of Brassica oleracea dietary antioxidants, International Journal of Food Science and Technology 41 (2006) 49-58.

[8]. Y. Tanongkankit, N. Chiewchan, S. Devahastin, Evolution of antioxidants in dietary fiber powder produced from white cabbage outer leaves: effects of blanching and drying methods, Journal of Food Science and Technology 52 (2015) 2280-2287.

[9]. V. Benítez, E. Mollá, M.A. Martín-Cabrejas, Y. Aguilera, F.J. López-Andréu, R.M. Esteban, Onion (Allium cepa L.) by-products as source of dietary fiber: physicochemical properties and effect on serum lipid levels in high-fat fed rats, European Food Research and Technology 234 (2012) 617 625.

[10]. C. Cabrera, F. Lloris, R. Gimenez, M. Olalla, M.C. Lopez, Mineral content in legumes and nuts: contribution to the Spanish dietary intake, Science of the Total Environment 308 (2003) 1-14.

[11]. M.C. Houston, K. J. Harper, Potassium, magnesium, and calcium: their role in both the cause and treatment of hypertension, The Journal of Clinical Hypertension 10 (2008) 3-11.

[12]. C. Bvenura, A.J. Afolayan, Heavy metal contamination of vegetables cultivated in home gardens in the Eastern Cape, South African Journal of Science 108 (2012) 1-6.
[13]. Z. Stančić, D. Vujević, A. Gomaz, S. Bogdan, D. Vincek, Detection of heavy metals in common vegetables at Varaždin City Market, Croatia, Archives of Industrial Hygiene and Toxicology 67 (2016) 340-350.

[14]. C. Radulescu, C. Stihi, I.V. Popescu, I.D. Dulama, E.D. Chelarescu, A. Chilian, Heavy metal accumulation and translocation in different parts of Brassica Oleracea L, Romanian Journal of Physics 58 (2013) 1337-1354.

[15]. A. Leahu, C. Damian, M. Oroian, S. Ropciuc, R. Rotaru Influence of processing on vitamin $\mathrm{C}$ content of rosehip fruits, Scientific Papers Animal Science and Biotechnologies 47 (2014) 116-120.

[16]. A. Harzallah, A. M Bhouri, Z. Amri, H. Soltana, M. Hammami, Phytochemical content and antioxidant activity of different fruit parts juices of three figs (Ficus carica L.) varieties grown in Tunisia, Industrial Crops and Products 83 (2016) 255-267.

[17]. M. Oroian, S. Amariei, A. Leahu, G. Gutt, Multielement composition of honey as a suitable tool for its authenticity analysis, Polish Journal of Food and Nutrition Sciences 65 (2015) 93-100.

Received: 21.05 .2018

Received in revised form: 29.10.2018

Accepted: 07.11.2018 